\title{
Inclusão social no mercado de trabalho de pacientes amputados em processo de reabilitação
}

\section{Social inclusion in the labor market of amputees in the process of rehabilitation}

Regina Hanashiroํㅜ, Viviane Duarte Correia ${ }^{1}$, Andre Tadeu Sugawara²

\section{RESUMO}

Objetivo: Conhecer o processo de inclusão social no mercado de trabalho, do paciente amputado, e identificar alterações socioeconômicas, após o processo de reabilitação, além de contribuir para o levantamento de dados socioeconômicos acerca da pessoa com deficiência. Método: Pesquisa retrospectiva, quantitativa e qualitativa, sob a perspectiva dialética. Os dados foram obtidos por meio do Protocolo de Avaliação Social Institucional e relatórios sociais dos pacientes amputados, que passaram pelo ambulatório, após alta do processo em um Centro de Reabilitação no município de São Paulo, no período de abril a setembro de 2016. Resultados: Os sujeitos da pesquisa (23) foram, em sua maioria do gênero masculino (20), em idade ativa (média simples de 39,5 anos), com nível de escolaridade no ensino médio (9). A maioria (21) absteve das atividades laborais. Após a instalação da deficiência, houve queda na renda familiar. Inicialmente, (17) usufruem de benefícios previdenciários, (1) benefício assistencial, e (4) estão em processo de solicitação de benefício. Durante o tratamento reabilitativo, houve redução dos benefícios previdenciários (de 17 para 15), aumento nos benefícios assistenciais (3), (1) aguarda concessão de benefício, e 3 obtiveram alta do INSS. Conclusão: Os resultados apontam que os pacientes amputados sofrem alterações socioeconômicas, após a instalação da deficiência, decorrentes à abstenção as atividades laborais e rebaixamento na renda, apontando para a importância da proteção previdenciária e assistencial. Fatores como idade, escolaridade e quantidade de internações favoreceram o retorno dos pacientes amputados no mercado de trabalho.

Palavras-chave: Pessoas com Deficiência, Amputação, Mercado de Trabalho, Readaptação ao Emprego

${ }^{1}$ Assistente Social, Instituto de Medicina Física e Reabilitação HCFMUSP

${ }^{2}$ Médico Fisiatra, Instituto de Medicina Física e Reabilitação HCFMUSP

\section{Correspondência}

Viviane Duarte Correia

E-mail: viviane.duarte@hc.fm.usp.br

Submetido: 17 Agosto 2018

Aceito: 27 Dezembro 2018

\section{Como Citar}

Hanashiro R, Correia VD, Sugawara AT. Inclusão social no mercado de trabalho de pacientes amputados em processo de reabilitação. Acta Fisiatr. 2018;25(3):138-144.

\section{ABSTRACT}

Objective: Raise awareness regarding social inclusion into the workforce of amputees, identify socio-economic changes due to the physical rehabilitation process, and promote a dataset of socio-economic data of people with disabilities. Method: This is a retrospective quantitative and qualitative research with a dialectical perspective. Data was collected by Institutional Social Evaluation Protocol of outpatients amputees after discharge of a rehabilitation facility in the city of São Paulo, Brazil, from April to September of 2016. Results: The subjects $(n=23)$ were generally male $(n=20)$, with an average of 39,5 years of age, mostly of which with high-school education $(n=9)$. Most of the patients $(n=23)$ did not resume labor activity. After amputation, reduction of income was observed. Initially, considering the period of data collection, seventeen subjects were under social security assistance, one subject benefited from another source of assistance, and four of them were handling the bureaucracy to receive such assistance. During the rehabilitation program, there was reduction of social security assistance (from 17 to 15), increase of assistance benefits $(n=3)$, three patients started receiving social security assistance, and one of them was released from the social security assistance list. Conclusion: The results suggest that amputees undergo socio-economic changes after the disability is onset, given the lack of labor activity, income reduction, what demand social security assistance. Characteristics such as age, education and number of hospitalizations favoured the amputees to resume their labor activities.

Keywords: Disabled Persons, Amputation, Job Market, Employment, Supported 


\section{INTRODUÇÃO}

A amputação é definida como a retirada cirúrgica, parcial ou total, de um segmento corpóreo, sendo esse procedimento cirúrgico, um dos mais antigos da história da humanidade. ${ }^{1}$ Ela remete a ideia de mutilação, incapacidade, impossibilidade de trabalhar, por isso a palavra é temida, principalmente, para o paciente. Entretanto, há de se considerar a amputação "não como o fim, mas como o princípio de uma nova fase: se por um lado mutilou a imagem corporal, por outro eliminou o perigo de perder a vida, dando alívio ao sofrimento". ${ }^{2} \mathrm{E}$ com o advento de novos medicamentos e as técnicas cirúrgicas de revestimento cutâneo, nos últimos tempos, o perfil das amputações mudou muito. ${ }^{1}$

Após a amputação, os pacientes abstêm das atividades laborativas, podendo perder a condição de prover sustento próprio e o de seus dependentes, sendo então, necessária a proteção previdenciária e assistencial. ${ }^{3}$ Essa interrupção, acarretada pela instalação da deficiência, atinge os pacientes tanto na esfera social, quanto na privada (família), podendo levá-los a uma situação de vulnerabilidade social temporária e/ou definitiva face às mudanças cotidianas, tanto na vida profissional, como no papel sócio familiar. Resignificar a vida cotidiana não é tarefa fácil.

Nesse sentido, torna-se relevante o programa de reabilitação o mais precocemente possível, pois "a reabilitação de um paciente amputado é um processo abrangente, multiprofissional e interdisciplinar, que envolve aspectos físicos, emocionais e sociais". 4

"A reabilitação é orientada por uma abordagem biopsicossocial voltada à deficiência e à incapacidade", ${ }^{5}$ cujo modelo não privilegia a etiologia, mensura a funcionalidade do indivíduo considerando aspectos socioambientais e levando em consideração a habilidade de participação em sociedade. Ela é eficaz na redução da carga da incapacidade e no aumento das oportunidades de inclusão social para as pessoas com deficiência cujo objetivo maior da reabilitação é garantir a autonomia e independência funcional às pessoas com deficiência.

A combinação de medidas para trabalhar a deficiência com as medidas para remover ou reduzir barreiras à participação do indivíduo em seu ambiente familiar e social, contribuem para que o objetivo seja atingido. Tendo como resultados fundamentais da reabilitação: o bem estar da pessoa e sua participação ativa na sociedade incluindo a profissionalização. ${ }^{5,6}$

Para um bom desenvolvimento do processo de reabilitação é necessário, um trabalho integral considerando as limitações físicas, psíquicas e ambientais, e não somente as limitações motoras, mas também, a inclusão no convívio familiar e social. Com isso, a identificação e análise dos fatores que intervém no processo reabilitativo, atentadas as especificidades de cada área, proporciona melhores resultados que rumam a objetivos comuns, tanto da equipe, quanto dos pacientes e familiares. ${ }^{7}$

O assistente social, no Instituto de Medicina Física e Reabilitação, contribui para a detecção de problemas e possibilidades sociais que garantam a participação do paciente no programa de reabilitação. Ademais, avalia sobre as condições sociais do paciente e familiar, interação com o meio, buscando minimizar os impactos da presença da deficiência, por meio de orientações acerca das políticas públicas e empoderamento para exercício de cidadania, contribuindo para a inclusão social, e objetivando a qualidade de vida. A metodologia de trabalho utilizada pelo profissional, neste espaço, é socioeducativa em modalidades individuais e/ou em grupos, durante o tratamento.

A atuação do assistente social, no contexto da Reabilitação, pode contribuir nos seguintes aspectos: adequação das expectativas para adesão do tratamento e da organização familiar necessária, bem como a prevenção da sobrecarga do cuidador/familiar; reflexão e elaboração de planos de vida futura (trabalho, renda, educação, lazer e outros) pós tratamento reabilitativo; contribuição para o fortalecimento do papel social e familiar do paciente; utilização dos recursos disponíveis no meio sócio comunitário; contribuição a equipe técnica (interdisciplinar), disponibilizando dados sobre a realidade social e familiar da pessoa com deficiência, sobre os quais serão alicerçados os planos terapêuticos e a condução do tratamento. ${ }^{8}$

Autores apontam que pacientes amputados, quando comparados às pessoas com sequelas decorrentes às doenças neuromusculares $\mathrm{e}$ acidente vascular cerebral, apresentam melhores taxas de retorno ao trabalho. ${ }^{9}$ Entretanto, tanto em países desenvolvidos, quanto em desenvolvimento as "pessoas com deficiência em idade de trabalhar apresentam baixas taxas de empregabilidade e taxas muito mais altas de desemprego do que pessoas sem deficiências". ${ }^{10}$

De acordo com a Cartilha do Censo 2010 da pessoa com deficiência, das 44 milhões de pessoas com pelo menos uma deficiência, em idade ativa (10 anos ou mais), 46\% (20,4 milhões) representam pessoas ocupadas e $54 \%$ (23,7milhões) não ocupadas. Das 117,9 milhões população sem deficiência, 56\% (66 milhões) representam pessoas ocupadas e $44 \%$ (51,9 milhões) não ocupadas. ${ }^{7}$

Diante desta premissa, estudos que possam conhecer o processo de inclusão social do paciente amputado, no mercado de trabalho, como também identificar alterações socioeconômicas do paciente, após o processo de reabilitação em regime de internação, contribuindo para o levantamento de dados socioeconômicos acerca da pessoa com deficiência.

\section{Inclusão social paciente amputado}

É certo que, o objetivo da reabilitação de pessoas com deficiência, seja a inclusão social, definida como processo pelo qual a sociedade se adapta para poder incluir as pessoas com deficiência e, ao mesmo tempo, estas se preparam para assumir o papel na sociedade (empoderamento), tendo em vista a equiparação de oportunidades; a inclusão abrange a participação social, educacional, profissional e nos serviços de saúde. ${ }^{11}$

A inclusão da pessoa com deficiência no mercado de trabalho tem impacto positivo para o paciente, como a conquista de crescentes graus de autonomia, bem como a obtenção de um novo papel na família e na comunidade. $O$ que tem superado as expectativas e oferecido aprendizagens importantes ao ambiente corporativo. ${ }^{12}$ No entanto, as atitudes da sociedade podem interferir de forma negativa na inclusão social, excluindo o indivíduo socialmente.

Considera-se que a "exclusão social é a apartação de uma inclusão pela presença da discriminação e do estigma". ${ }^{13}$ Infelizmente, ainda há preconceito e estigmas presentes em nossa sociedade, face ao ranço histórico que ainda exista, em relação à pessoa com deficiência, tornando uma barreira para a inclusão social da pessoa com deficiência.

Tendo em vista que, "alguns dos principais problemas das pessoas com deficiência tem origem na sociedade, ou seja, decorrem de barreiras sociais e não das barreiras funcionais decorrentes da sua limitação". ${ }^{14}$ O rompimento dessas barreiras requer esforços políticos, políticas públicas que promovam a inclusão social das pessoas com deficiência na sociedade.

Dentre as políticas estruturais temos: as políticas educacionais como escolas inclusivas com professores treinados e especializados; políticas de saúde, a reabilitação para adequação a nova condição de vida e desenvolvimento ao longo do tempo; investimentos em tecnologias voltados a reduzir barreiras funcionais como avanços da informática e telecomunicações que possibilitam a inclusão no mercado de trabalho.

Quanto às medidas legislativas principais canais para coibir a discriminação e incentivar as empresas a contratarem pessoas com deficiência e também políticas operacionais como ações de comunicação, transporte, ambientais (acessibilidade arquitetônica) e seguridade social. ${ }^{14}$

A participação social visa a melhora da qualidade de vida do paciente, sendo o entendimento da qualidade de vida como fator de importância na percepção do sujeito sobre sua saúde, e segundo a Organização Mundial da Saúde (OMS) a qualidade de vida é "a 
percepção do indivíduo de sua posição na vida, no contexto de sua cultura e no sistema de valores e em relação ás suas expectativas, padrões e preocupações", considerando como requisitos indispensáveis à qualidade de vida a interação com o meio social em que está inserido, o acesso aos bens e aos serviços disponibilizados aos demais cidadãos, o reconhecimento do seu próprio papel e de sua importância dentro do núcleo familiar e da comunidade. ${ }^{5}$ É importante que a sociedade se conscientize dando a oportunidade para que as pessoas com deficiência tenham acesso aos bens e que façam parte da sociedade como todo.

No Brasil, foram promulgadas leis no intuito de promover a inclusão social no mercado de trabalho, no qual citaremos duas, que se consideram mais importantes. Uma delas atua na esfera pública e é a reserva legal de vagas para pessoas com deficiência nos concursos públicos, conforme Lei no 8.112/90, Art. 5요 § 2 은

Às pessoas portadoras de deficiência é assegurado o direito de se inscrever em concurso público para provimento de cargo cujas atribuições sejam compatíveis com a deficiência de que são portadoras; para tais pessoas serão reservadas até $20 \%$ (vinte por cento) das vagas oferecidas no concurso. ${ }^{15}$

A segunda se destina a iniciativa privada e está inserida na lei geral da previdência social, artigo 93 da Lei 8.213/91.

A empresa com 100 (cem) ou mais empregados está obrigada a preencher de $2 \%$ (dois por cento) a $5 \%$ (cinco por cento) dos seus cargos com beneficiários reabilitados ou pessoas portadoras de deficiência, habilitadas, na seguinte proporção: ${ }^{16}$

1 - até 200 empregados..... 2\%;

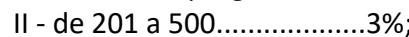

III - de 501 a $1.000 \ldots \ldots \ldots . . . . . .4 \%$;

IV - de 1.001 em diante....... 5\%.

Outra ação afirmativa para a inclusão da pessoa com deficiência no mercado de trabalho é a Reabilitação Profissional, que consiste num serviço do INSS que tem o objetivo de oferecer aos segurados incapacitados para o trabalho, por motivo de doença ou acidente, os meios de reeducação ou readaptação profissional para o seu retorno ao mercado de trabalho em outra função. ${ }^{17}$

Em 02 de janeiro de 2016 entrou em vigor a Lei Brasileira de Inclusão (Lei 13.146/2015), sancionada em 2015, que garante uma série de direitos nas áreas de educação, trabalho, habitação, cultura e lazer aos 45 milhões de brasileiros com deficiência no país, e impõe sanções para atitudes discriminatórias, especialmente no âmbito do trabalho. A Lei avança em cidadania, ao tratar de questões relacionadas a acessibilidade, educação, trabalho e ao combate ao preconceito e discriminação.

As políticas públicas são necessárias para que ocorra a mudança no quadro de exclusão social da pessoa com deficiência no mercado de trabalho. Contudo, inclusão no mercado de trabalho, não deve ser feita apenas por obrigação da legislação, mas sim como oportunidade para que pessoas com deficiência coloquem suas habilidades em prática, desenvolvam-se e atinjam seus objetivos.

Para promover o ingresso e a participação da pessoa com deficiência no mercado de trabalho sugere-se a implantação de programas específicos para atender pessoas com deficiência, voltados à capacitação, desenvolvimento, integração, retenção, acessibilidade, entre outros, que demonstrem o compromisso da empresa com ampliação do acesso e inclusão das pessoas com deficiência.

Assim, o acompanhamento da efetivação das políticas públicas para a inclusão no mercado de trabalho, se faz necessária e imprescindível para a retomada de suas atividades.

Considera-se também que, além do fato do retorno ao trabalho contribuir para redução de pagamentos de benefícios previdenciários e aposentadorias é importante ressaltar que a inserção laboral faz parte da inclusão social.

O trabalho integra o conjunto de direitos sociais previstos no artigo 6o da Constituição Brasileira de 1988, que garante a todo cidadão o acesso à educação, à saúde ao lazer, ao trabalho, ao lazer, a segurança, a previdência social, entre outros.
Exercer um ofício, faz com que a pessoa humana sinta inserida e incluída com o meio social em que vive. E acrescenta que, a participação do homem nos meios de produção, além do caráter da inclusão, tem outra vertente prevista no art. 170 da Constituição Federal, a de contribuir para a ordem econômica e seu crescimento, na qual uma vez empregada a pessoa com deficiência, "além de participar do desenvolvimento do país, também gera riqueza, já que passa a ser consumidora". ${ }^{18}$

\section{OBJETIVO}

Conhecer a inclusão social do paciente amputado, no mercado de trabalho, como também identificar alterações socioeconômicas do paciente, após o processo de reabilitação e contribuir para o levantamento de dados socioeconômicos acerca da pessoa com deficiência.

\section{MÉTODOS}

Trata-se de pesquisa retrospectiva, quantitativa e qualitativa sob a perspectiva dialética. Para tanto, a pesquisa utilizou-se da revisão de prontuários de pacientes amputados por etiologias diferentes, de todos os níveis de amputação em membros inferiores e superiores, de ambos os sexos, que passaram em atendimento ambulatorial, após alta da internação, no período de abril a setembro de 2016.

Foram excluídos os pacientes sem o diagnóstico clínico e funcional de amputação (6), e os pacientes que não compareceram para atendimento ambulatorial (2). Assim, o total da amostra da pesquisa foi de 23 prontuários analisados $(\mathrm{N}=23)$. É oportuno atentar que, os pacientes sujeitos da pesquisa, estão em diferentes momentos do processo de reabilitação, em regime de internação.

Os dados coletados, do prontuário eletrônico, estão contidos na avaliação social e relatórios sociais tais como: idade; sexo; grau de escolaridade; município de procedência; tipo de amputação; etiologia; ocupação; composição familiar, renda per capta; planos futuros; situação previdenciária e trabalhista inicial e atual. A tabulação dos dados foi realizada por meio estatístico, entre as variáveis coletadas.

Para a tabulação da faixa etária, foi considerada a definição de população jovem pessoas de 15 a 24 anos, ${ }^{19}$ enquanto as pessoas idosas, com idade igual ou superior a 60 (sessenta) anos. ${ }^{20}$

Quanto à classificação das famílias foi utilizada a classificação dos novos arranjos familiares: ${ }^{21}$

- Família nuclear, tradicional é formada essencialmente por um homem, sua esposa, e seus filhos.

- $\quad$ Famílias monoparentais, são aquelas onde as pessoas vivem sem cônjuge, com um ou vários filhos solteiros, é aquela na qual vive um único progenitor com os filhos que não são ainda adultos.

- Família unipessoal é aquela composta por apenas uma pessoa.

- $\quad$ Famílias recompostas, quando houver nova união conjugal e que, dessa união, novos sujeitos históricos venham a existir.

- Família extensa resulta da extensão, no tempo e por intermédio de laços de casamento, das relações entre pais e filhos. Também corresponde ao grupo formado por um casal e as famílias conjugais de todos os seus descendentes.

- Família anaparental se caracteriza pela família sem a presença dos pais, resulta da colateralidade de vínculos, então ela pode ser composta por vários irmãos, ou dos tios e sobrinhos, ou então duas primas, dentre tantas outras possibilidades. ${ }^{22}$

A classificação das atividades foi de acordo com conceitos da Classificação Brasileira de Ocupações (CBO) cujo documento codifica empregos e outras situações de trabalho para fins estatísticos de registros administrativos, censos populacionais e outras pesquisas domiciliares. Inclui códigos e títulos ocupacionais e a descrição sumária. 
É dividido em Grupos e Subgrupos de acordo com competências e atividades executadas. ${ }^{23} \mathrm{Na}$ presente pesquisa foi utilizada a classificação dos Grandes Grupos proporcionando o conhecimento de sua ocupação por nível de escolaridade e competência que the é atribuída. Conforme segue: ${ }^{23}$

GG0 Forças Armadas, policiais e bombeiros militares;

GG1 Membros superiores do poder público, dirigentes de organizações de interesse público e de empresas e gerentes;

GG2 Profissionais das ciências e das artes (requer nível superior);

GG3 Técnicos de nível médio (conhecimento técnico);

GG4 Trabalhadores de serviços administrativos (burocráticos);

GG5 Trabalhadores dos serviços, vendedores do comércio em lojas e mercados como também de proteção e segurança, atividades domésticas, entre outros

GG6 Trabalhadores agropecuários, florestais, da caça e pesca

GG7 Trabalhadores da produção de bens e serviços industriais (construção civil e produção industrial). Exemplo: Montadores de aparelhos e instrumentos de precisão e musicais; joalheiros, vidreiros, ceramistas e afins.

GG8 Trabalhadores da produção de bens e serviços industriais, como por exemplo, Trabalhadores de instalações siderúrgicas e de materiais de construção; Trabalhadores de instalações e máquinas de fabricação de celulose e papel; Trabalhadores da fabricação de alimentos, bebidas e fumo.

GG9 Trabalhadores de manutenção e reparação (manutenção mecânica).

Buscou-se também, correlacionar os dados com os aspectos sociais, sob a perspectiva materialista dialética, a fim de não limitar apenas nas descrições dos dados, mas trazer a análise contextual do paciente amputado.

\section{RESULTADOS}

Os resultados apresentados a seguir serão expostos por meio de recursos gráficos. Os resultados serão apresentados em números absolutos (N) e percentual (\%), na Tabela 1.

Os dados apresentados no Quadro 1 contribuem para a identificação do perfil social dos pacientes que retornaram ao trabalho, sendo evidenciados os 6 pacientes que retornaram ao mercado de trabalho em P1; P2; P3; P4; P5 e P6, do total geral da amostra $\mathrm{N}=23$ sendo que na primeira internação $\mathrm{N}=9$, na segunda $\mathrm{N}=10$ e terceira $\mathrm{N}=4$.

\section{DISCUSSÃO}

Os pacientes participantes da pesquisa foram compostos em sua maioria, por pessoa do sexo masculino, a maior ocorrência foi em pessoas com idade de 25 a 50 anos, atentando para o grupo etário em idade produtiva; quanto à escolaridade o predomínio do ensino médio. Observa-se que todos os sujeitos da pesquisa tiveram acesso à educação, fator que contribui para a inclusão social no mercado de trabalho.

Sugere-se que pessoas que tenham a instalação da deficiência adquirida na fase adulta, apresentam maior nível de escolaridade e maior possibilidade de inclusão social, quando comparadas às crianças e jovens com deficiência, em que o Relatório Mundial sobre Deficiência aponta barreiras enfrentadas no acesso à educação para esta população. ${ }^{10}$ Houve predomínio de pacientes procedentes da região metropolitana de São Paulo, com famílias cuja composição é nuclear.

Destaca-se também, a diversidade dos tipos de arranjos familiares, apontando a atenção profissional na condução das orientações,

$a_{\text {Benefícios Previdenciários dependem, em sua maioria, de um número mínimo de contribuições }}$ mensais (periodo de carência) para que o segurado faça jus ao benefício. Abrangem as aposentadorias, as pensões por morte, os auxilios, o salário-família e o salário-maternidad e.

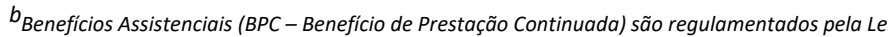
Orgânica da Assistência Social - LOAS, que garantem um salário mínimo mensal a idosos com 65 quanto aos cuidados e aos exercícios a serem realizados no domicílio, devendo ser ajustadas ao perfil de cada família. ${ }^{24}$

A família tem um papel importante e imprescindível para a continuidade e adesão ao tratamento reabilitativo: "a família, independente do arranjo familiar ou da forma como vem se estruturando, é o espaço indispensável para o desenvolvimento da proteção integral dos filhos e demais membros". ${ }^{24}$

É preciso respeitar cada perfil, evitando-se fazer julgamentos de valor, que possam gerar sentimento de culpa nos familiares portadores de um rol de emoções já tão difíceis de serem vividas. ${ }^{10}$

$A$ intervenção relacionada à dinâmica familiar envolve o resgate da vida social e vínculos familiares com a família extensa, orientações sobre os papéis sociais e inversão de papéis familiares, sobre a importância da adesão da família ao tratamento, visando sensibilização para a inclusão, e planejamento de estratégias para o enfretamento das dificuldades vivenciadas no cotidiano. ${ }^{7}$

Quanto aos aspectos socioeconômicos, os resultados apontam alterações, após a instalação da deficiência, como abstenção as atividades laborais e rebaixamento na renda, bem como a necessidade de proteção previdenciária e assistencial. Tais dados evidenciam o impacto econômico, após a instalação da deficiência, não atrelada, necessariamente, a situação de vulnerabilidade, mas a longo prazo, pode levar a tal.

Quanto a questão previdenciária, no início do tratamento reabilitativo, do total da amostra, 17 mantinham benefício previdenciário $^{a}$ e 01 benefício assistencial ${ }^{b}(B P C)$, para manutenção econômica.

Ainda no total da amostra, 04 estavam no aguardo de análise previdenciária e 01, manteve suas atividades laborais. Dos que aguardavam o desfecho da solicitação de benefício previdenciário (4), para 1 foi concedido auxílio-doença e 2 o BPC, e 1 continua no aguardo de benefício, em processo judicial. Portanto, durante o tratamento reabilitativo, o número de pacientes que receberam benefício auxilio doença reduziu de 14 para 12. Entretanto, o número de concessão de benefício assistencial subiu de 1 para 3 .

Dos que iniciaram o Programa de Reabilitação, com benefício de auxilio doença (14), 3 deles receberam alta do INSS, após o tratamento. Ressaltando que foram aqueles que completaram as três fases do processo de reabilitação, em regime de internação.

Os dados corroboram com o estudo de pessoas amputadas, em que durante o processo de reabilitação, a vida produtiva fica suspensa, refletindo impacto econômico no grupo familiar. ${ }^{25}$ No entanto, tem possibilidade de retornar ao trabalho.

O acompanhamento do profissional de Serviço Social no tratamento de reabilitação é imperativo, na perspectiva da inclusão social, com ênfase ao direcionamento para as políticas públicas, programas e acesso a benefícios e serviços, atentando ao impacto familiar e enfrentamento da condição de saúde.

Quanto aos planos futuros a maioria almeja retornar ao mercado de trabalho. Tais dados são importantes para nortear a garantia da adesão e auxiliar a equipe na definição de metas e objetivos do tratamento, com vistas a melhora da qualidade de vida.

No que se refere ao tipo de amputação a predominância foi de $61 \%$ pacientes amputados de membros inferiores, sendo $86 \%$ de etiologia traumática.

Dentre os processos de internações, do total de 23 pacientes, 6 retornaram as atividades de trabalho. Destes, 3 pacientes retornaram ao trabalho na mesma função exercida, anterior a deficiência porém, apenas 1 paciente retornou com vínculo empregatício, os outros 02 pacientes estão sem vínculo com a empresa. Dos 3 pacientes não retornaram na mesma função anterior, 2 exercem as atividades sem vínculo empregatício e 01 como voluntário (Quadro 1). 
Tabela 1. Perfil social dos pacientes ampudos

\begin{tabular}{|c|c|c|}
\hline Total amostra $\mathrm{N}=\mathbf{2 3}$ & $(\mathrm{N})$ & $\%$ \\
\hline \multicolumn{3}{|l|}{ Gênero } \\
\hline Feminino & 3 & $13 \%$ \\
\hline \multicolumn{3}{|l|}{ Município de procedência } \\
\hline São Paulo (Capital) & 8 & $35 \%$ \\
\hline Região Metropolitana de São Paulo & 7 & $31 \%$ \\
\hline \multicolumn{3}{|l|}{ Idade } \\
\hline 15 a 24 anos & 5 & $22 \%$ \\
\hline 25 a 59 anos & 15 & $65 \%$ \\
\hline 60 anos ou mais & 3 & $13 \%$ \\
\hline \multicolumn{3}{|l|}{ Escolaridade } \\
\hline Ensino fundamental incompleto & 6 & $26 \%$ \\
\hline Ensino fundamental completo & 1 & $4 \%$ \\
\hline Ensino médio incompleto & 2 & $9 \%$ \\
\hline Ensino médico completo & 9 & $39 \%$ \\
\hline Superior completo & 5 & $22 \%$ \\
\hline \multicolumn{3}{|l|}{ Composição Familiar } \\
\hline Anaparental & 1 & $4 \%$ \\
\hline Casal Sem filhos & 2 & $9 \%$ \\
\hline Extensa & 7 & $31 \%$ \\
\hline Monoparental & 2 & $9 \%$ \\
\hline Nuclear & 9 & $39 \%$ \\
\hline Recomposta & 1 & $4 \%$ \\
\hline Unipessoal & 1 & $4 \%$ \\
\hline \multicolumn{3}{|l|}{ Renda per capta } \\
\hline Até $\mathrm{R} \$ 220,00$ & 2 & $8 \%$ \\
\hline $\mathrm{R} \$ 221,00$ a $\mathrm{R} \$ 440,00$ & 5 & $22 \%$ \\
\hline $\mathrm{R} \$ 441,00$ a $\mathrm{R} \$ 880,00$ & 7 & $30 \%$ \\
\hline $\mathrm{R} \$ 881,00$ a $\mathrm{R} \$ 1.760,00$ & 5 & $22 \%$ \\
\hline Acima de $\mathrm{R} \$ 1.760,00$ & 2 & $9 \%$ \\
\hline Não declarou renda & 2 & $9 \%$ \\
\hline \multicolumn{3}{|c|}{ Rebaixamento do Status econômico após a instalação da deficiência } \\
\hline Sim & 19 & $82 \%$ \\
\hline Não & 2 & $9 \%$ \\
\hline Não informado & 2 & $9 \%$ \\
\hline \multicolumn{3}{|l|}{ Acompanhamento da Situação Previdenciária (inicial) } \\
\hline Aposentadoria por Invalidez & 2 & $9 \%$ \\
\hline Aposentadoria por tempo de contribuição & 1 & $4 \%$ \\
\hline Auxilio Doença & 14 & $64 \%$ \\
\hline Benefício de Prestação continuada - BPC & 1 & $5 \%$ \\
\hline Sem renda - Em processo de Solicitação & 4 & $18 \%$ \\
\hline \multicolumn{3}{|l|}{ Acompanhamento da Situação Previdenciária (após internação) } \\
\hline Aposentadoria por Invalidez & 2 & $9 \%$ \\
\hline Aposentadoria por tempo de contribuição & 1 & $4 \%$ \\
\hline Auxilio Doença & 12 & $55 \%$ \\
\hline Benefício de Prestação continuada - BPC & 3 & $14 \%$ \\
\hline Sem renda - Em processo de Solicitação & 1 & $4 \%$ \\
\hline Alta INSS & 3 & $14 \%$ \\
\hline \multicolumn{3}{|l|}{ Ocupação (CBO) } \\
\hline Forças Armadas, policiais e bombeiros militares; & 1 & $4 \%$ \\
\hline Profissionais das ciências e das artes (nível superior); & 4 & $18 \%$ \\
\hline Técnicos de nível médio & 2 & $9 \%$ \\
\hline Trabalhadores de serviços administrativos & 1 & $4 \%$ \\
\hline Trabalhadores dos serviços & 6 & $26 \%$ \\
\hline Trabalhadores agropecuários & 4 & $17 \%$ \\
\hline Trabalhadores da produção de bens e serviços industriais & 3 & $13 \%$ \\
\hline Trabalhadores de manutenção e reparação & 2 & $9 \%$ \\
\hline \multicolumn{3}{|l|}{ Abstenção da atividade laboral, após a instalação da deficiência } \\
\hline Sim & 21 & $91 \%$ \\
\hline Não & 2 & $9 \%$ \\
\hline Planos Futuros & & \\
\hline Trabalho & 14 & $61 \%$ \\
\hline Vida Social & 3 & $13 \%$ \\
\hline Esportes & 2 & $9 \%$ \\
\hline Sem planejamento Futuro & 4 & $17 \%$ \\
\hline Interesse em qualificação Profissional & & \\
\hline Sim & 9 & $39 \%$ \\
\hline Não & 14 & $61 \%$ \\
\hline Tipos de amputação & & \\
\hline Membros Superiores & 1 & $4 \%$ \\
\hline Membros Inferiores & 22 & $96 \%$ \\
\hline Etiologia das Amputações & & \\
\hline Traumática & 14 & $61 \%$ \\
\hline Não Traumática & 9 & $39 \%$ \\
\hline
\end{tabular}

No Brasil, a Lei de $\operatorname{Cotas}^{16}$ é uma garantia legal de acesso ao mercado de trabalho para as pessoas com deficiência. Entretanto, o único paciente que voltou ao mercado, com vínculo empregatício, retornou sem usufruir desta lei. Sugere-se aprofundamento em pesquisas que avaliem o acesso das pessoas com deficiência na política pública de empregabilidade, com vistas à efetivação desta, enquanto aparato legal.

Os dados apontam que o retorno ao mercado de trabalho informal é prevalente (4) nesta pesquisa, embora nem todos os pacientes tenham atingido o término do tratamento.

Os dados corroboram com o relatório mundial da pessoa com deficiência, ${ }^{10}$ que refere o predomínio do trabalho informal e autônomo das pessoas com deficiência em vários países, devido à necessidade de flexibilidade de horários para locomoção e cuidados com a saúde.

No entanto, torna-se importante ressaltar que, com o trabalho informal o empregado fica sem o amparo da legislação trabalhista, além de subestimar os resultados das pesquisas acerca da inclusão de pessoas com deficiência no mercado de trabalho, por este considerar o mercado de trabalho formal. ${ }^{10}$ Os indicadores estatísticos são importantes para a fomentação de políticas públicas.

Quanto ao vínculo previdenciário do total de pacientes que retornaram as atividades (6), 03 continuam recebendo benefício auxílio-doença, 01 recebe o benefício de aposentadoria por invalidez e apenas 02 pacientes tiveram alta do INSS.

Observa-se predominância de retorno ao trabalho 67\% (4) mesmo sem liberação INSS. Estudos apontam que pessoas com deficiência deixam de trabalhar para não perderem o benefício, devido às dificuldades encontradas em renunciar um direito para competir por um emprego e enfrentar barreiras de acessibilidade urbana e nas empresas, o que pode acarretar o interesse pelo benefício em vez do risco e dificuldades e insegurança para trabalhar. ${ }^{26}$

Sendo à atuação do assistente social de suma importância, pois a falta de informação e orientações pode representar uma barreira para a inclusão social. Sugere-se a intervenção focada em conscientização para as políticas públicas (Lei de Cotas) e interface com serviços que acompanhem e estimulem a contratação da pessoa com deficiência.

Outra característica comum, é a presença de pacientes no exercício de atividades de trabalho informais em todas as fases do tratamento.

Estes fatores apontam para estratégia de manutenção financeira, diante do impacto socioeconômico, verificado na amostra em que $100 \%$ (6) desses pacientes, deixaram de exercer suas atividades laborais após a instalação da deficiência e apontam também uma queda na renda neste período.

Diante do impacto econômico, acarretando a necessidade de retorno ao trabalho, como aponta a tabela acima, o programa de reabilitação se faz imperativo, com vistas à redução da carga da incapacidade, aumento da autonomia e independência funcional, rompimento de barreiras, contribuindo para a inclusão social no mercado de trabalho com a garantia e efetivação dos seus direitos sociais.

No cenário da presente pesquisa, 3 pacientes $(50 \%)$ passaram pelo terceiro processo reabilitativo de internação, 2 (33\%) pelo segundo processo e 1 (17\%) pelo primeiro processo. Observa-se que, o aumento gradativo de retorno ao trabalho conforme o aumento do número de internação.

Ressaltando que, os pacientes ainda não finalizaram o programa de reabilitação, estando assim no aguardo de novas internações para continuidade do tratamento.

Dentre o perfil dos pacientes que retornaram ao trabalho, manteve-se a prevalência do perfil geral. Diante do exposto, considera-se que a maioria dos pacientes amputados, desta pesquisa, apresenta potencial para retorno ao trabalho, tendo em vista características sociais que favorecem a inclusão social no mercado de trabalho, tais como: idade, escolaridade, projeções de retorno ao trabalho, e situação econômica. 
Quadro 1. Perfil dos pacientes que retornaram ao mercado de trabalho

\begin{tabular}{|c|c|c|c|c|c|c|}
\hline & P1 & $\mathbf{P 2}$ & P3 & P4 & P5 & P6 \\
\hline Gênero & Masculino & Feminino & Masculino & Masculino & Masculino & Masculino \\
\hline Idade & 47 anos & 48 anos & 34 anos & 41 anos & 37 anos & 64 anos \\
\hline Escolaridade & Médio & Fundamental & Superior & Fundamental & Superior & Superior \\
\hline Município de Procedência & Franco da Rocha & Mogi das Cruzes & Cajamar & Mairiporã & $\begin{array}{l}\text { São Caetano do } \\
\text { Sul }\end{array}$ & São Paulo \\
\hline Composição Familiar & Casal sem filhos & Nuclear & Nuclear & Nuclear & Monoparental & Nuclear \\
\hline Quantidade de Internação & $\begin{array}{l}\text { 3ạ } \\
\text { Internação }\end{array}$ & $\begin{array}{l}2^{\mathrm{a}} \\
\text { Internação }\end{array}$ & $\begin{array}{l}3^{a} \text { a } \\
\text { Internação }\end{array}$ & $\begin{array}{l}\text { 1ạ } \\
\text { Internação }\end{array}$ & $\begin{array}{l}2^{\text {a }} \\
\text { Internação }\end{array}$ & $\begin{array}{l}\text { 3ạ } \\
\text { Internação }\end{array}$ \\
\hline Rebaixamento do Status Econômico & Sim & Sim & Sim & Sim & Sim & Sim \\
\hline $\begin{array}{l}\text { Abstenção a Atividade Laboral após } \\
\text { Instalação da Deficiência }\end{array}$ & Sim & Sim & Sim & Sim & Sim & Sim \\
\hline Atividade Anterior & GG5 & GG5 & GG5 & GG7 & GG 9 & GG2 \\
\hline Atividade Atual & GG5 & GG4 & GG5 & GG7 & GG5 & GG2 \\
\hline Retornou para a mesma função & Sim & Não & Sim & Não & Não & Sim \\
\hline $\begin{array}{l}\text { Com Vínculo Empregatício (atividade } \\
\text { atual) }\end{array}$ & Não & Não & Sim & Não & Não & Não \\
\hline $\begin{array}{l}\text { Sem vínculo Empregatício (atividade } \\
\text { atual) }\end{array}$ & Sim & Não & Não & Sim & Sim & Sim \\
\hline Voluntária (atividade atual) & Não & Sim & Não & Não & Não & Não \\
\hline Situação Previdenciária & Alta INSS & $\begin{array}{l}\text { Aposentadoria } \\
\text { por invalidez }\end{array}$ & Alta INSS & Auxilio Doença & Auxilio Doença & $\begin{array}{l}\text { Auxílio Doença / } \\
\text { Aposentado } \\
\text { Regime Próprio } \\
\text { (Estatutário) }\end{array}$ \\
\hline Tipo de Amputação & $\begin{array}{l}\text { Membro } \\
\text { Inferior }\end{array}$ & $\begin{array}{l}\text { Membro } \\
\text { Inferior }\end{array}$ & $\begin{array}{l}\text { Membro } \\
\text { Inferior }\end{array}$ & $\begin{array}{l}\text { Membro } \\
\text { Inferior }\end{array}$ & $\begin{array}{l}\text { Membro } \\
\text { Inferior }\end{array}$ & $\begin{array}{l}\text { Membro } \\
\text { Inferior }\end{array}$ \\
\hline Etiologia & Traumática & $\begin{array}{l}\text { Vascular } \\
\text { (Diabetes) }\end{array}$ & Traumática & Traumática & Traumática & $\begin{array}{l}\text { Vascular } \\
\text { (Diabetes) }\end{array}$ \\
\hline Planos Futuros & Trabalho & $\begin{array}{l}\text { Sem } \\
\text { planejamento } \\
\text { Futuro }\end{array}$ & Trabalho & Trabalho & Trabalho & Trabalho \\
\hline
\end{tabular}

\section{CONCLUSÃO}

Este trabalho é imperativo ao acompanhamento da inclusão social no mercado de trabalho, de pacientes amputados, em programa de reabilitação, na perspectiva social. Corroborou para trazer à tona, reflexões e ponderações sobre as práticas profissionais, atreladas aos objetivos do tratamento de reabilitação.

A análise do perfil social aponta eixos norteadores para as intervenções sociais, relacionadas ao apoio do paciente frente à nova situação, resgate a vida social, fortalecimento de vínculos familiares, orientações quanto à importância a adesão ao tratamento, as políticas públicas de acesso, sobretudo orientações frente à dinâmica do mercado de trabalho, auxiliando no dimensionamento das ações, no sentido de promover a equidade social e econômica. Para tanto, sugere-se ações que incentivem os pacientes e que estejam articuladas a serviços de capacitação profissional, tendo em vista as possibilidades de readaptações nas funções laborais.

Nota-se a potencialidade dos pacientes para o retorno ao trabalho no que se refere ao gênero, escolaridade, idade, o que ressalta a importância do programa de reabilitação, tendo em vista a redução da carga da incapacidade, aumento da autonomia e independência funcional, rompimento de barreiras, contribuindo para o retorno as atividades laborais. Do total da amostra, 06 pacientes exercem alguma atividade, o número de retorno cresce na proporção do aumento da quantidade de internações evidenciando que o resultado seja longo prazo.

O trabalho tem um papel determinante na inclusão social, como também econômica, pois no ambiente de trabalho, a pessoa com deficiência tem a possibilidade de romper com estigmas e demonstrar sua capacidade e produtividade. Assim, o acompanhamento da efetivação das políticas públicas para a inclusão no mercado de trabalho, se faz necessária e imprescindível para a retomada de suas atividades.

Para tanto, a equipe multiprofissional necessita estar integradas as aspirações individuais dos pacientes e familiares, após tratamento reabilitativo, direcionando o valor da inclusão social ao avanço do acesso às políticas públicas.

\section{REFERÊNCIAS}

1. Carvalho JA. Amputações de membros inferiores: em busca da plena reabilitação. 2 ed. Barueri: Manole; 2003.

2. Boccolini F. Reabilitação: Amputados, amputações, próteses. 2 ed. São Paulo: Robe; 2000.

3. Spichler D, Miranda Junior F, Spichler ES, Franco LJ. Amputações maiores de membros inferiores por doença arterial periférica e diabetes melito no município do Rio de Janeiro. J Vasc Bras. 2004;3(2):111-22.

4. Chamlian TR. Reabilitação de amputados de membros inferiores. In: Greve JMA. Tratado de medicina de reabilitação. São Paulo: Roca; 2007. p. 866-74.

5. Battistella LR. Reabilitação para inclusão social. In: Schewinsky SR, Kawamoto KA, Cichon FR, et al. Atrofia de múltiplos sistemas: neurologia e reabilitação. São Paulo: LMP; 2011. p. 271-80.

6. Correia VD. Avaliação social baseada na Classificação Internacional de Funcionalidade, Incapacidade e Saúde em crianças com paralisia cerebral [Dissertação]. São Paulo: Pontifícia Universidade Católica de São Paulo; 2016. 
7. Sasso SM, Kuss VLS, Bortoli J, Carraro E. A importância da interdisciplinaridade na prática da reabilitação física de amputados [texto na Internet] In: Simpósio Internacional sobre Interdisciplinaridade no Ensino, na Pesquisa e na Extensão Região Sul; 2013 Out 23-25; Florianópolis. Disponível em: http://www.siiepe.ufsc.br/wp-content/uploads/2013/10/I-Sassob.pdf

8. Salimene ACM. A importância da triagem dos amputados candidatos a reabilitação e o Serviço Social. São Paulo: IMREA; 2011.

9. Guarino $P$, Chamlian TR, Masiero D. Retorno ao trabalho em amputados dos membros inferiores. Acta Fisiátr. 2007;14(2):1003.

10. World Health Organization. Relatório mundial sobre a deficiência. São Paulo: SEDPCD; 2012.

11. Sassaki RK. Inclusão: construindo uma sociedade para todos. 7 ed. Rio de Janeiro: WVA; 1997.

12. Melo JR. Apresentação. In: Carmo JC. Construindo a inclusão da pessoa com deficiência no trabalho: a experiência da indústria da construção pesada no Estado de São Paulo. São Paulo: Áurea; 2011. p. 10-3.

13. Sposati A. A fluidez da inclusão/exclusão social. Cienc Cult. 2006;58(4):4-5.

14. Neri $M$, Pinto A, Soares $W$, Costilla $H$. Retratos da deficiência no Brasil. Rio de Janeiro: FGV/IBRE; 2003.

15. Brasil. Lei n. 8.112, de 11 de dezembro de 1990. Dispõe sobre o regime jurídico dos servidores públicos civis da União, das autarquias e das fundações públicas federais. Diário Oficial da República Federativa do Brasil, Brasília (DF): 1990 Dez 12; Seção 1:23935-46.

16. Brasil. Lei n. 8.213, de 24 de julho de 1991. Dispõe sobre os planos de benefícios da previdência social e dá outras providencias. Diário Oficial da República Federativa do Brasil, Brasília (DF): 1991 Jul 25; Seção 1:14809-19.
17. Instituto Nacional do Seguro Social. Programa de educação previdenciária [CD- ROM]. São Paulo: Gerencia Executiva INSS; 2016.

18. Ragazzi IAG. Inclusão social: a importância do trabalho da pessoa portadora de deficiência. São Paulo: LTR; 2010.

19. Sistema Estadual de Análise de Dados. Pesquisa de emprego e desemprego na região do $A B C$ [texto na Internet]. São Paulo: SEADE; [citado 2016 Dez 14]. Disponível em: http://www.seade.gov.br/produtos/midia/estudosped/abc/estu doJovensABCjul2013.pdf

20. Brasil. Lei n. 10.741 , de 1 de outubro de 2003. Dispõe sobre o Estatuto do Idoso e dá outras providências. Diário Oficial da República Federativa do Brasil, Brasília (DF): 2003 Out 3; Seção 1:16.

21. Trad LAB. Família Contemporânea e Saúde: Significados práticas e políticas públicas. Rio de Janeiro: Fiocruz; 2010.

22. Kusano S. Da família anaparental: do reconhecimento como entidade familiar. Ambito Jurídico. 2010; XIII (70).

23. Classificação Brasileira de Ocupações: códigos, títulos e descrições. 3a ed. Brasília: MTE/SPPE; 2010.

24. Borgneth LRL, Hassano AYS. Equipe de reabilitação. In: Greve JMA. Tratado de medicina de reabilitação. São Paulo: Roca; 2007. p. 57.

25. Lorenzo SM. Inserção de pessoas com deficiências no mercado formal de trabalho a partir da percepção dos profissionais de recursos humanos das empresas [Dissertação]. Marília: Universidade Estadual Paulista "Júlio de Mesquita Filho"; 2016.

26. Dornellas LF. Uso da prótese e retorno ao trabalho em amputados por acidentes de transporte. Acta Ortop Bras. 2010;18(4):204-6. DOI: http://dx.doi.org/10.1590/S1413-78522010000400006 